Itinéraires Itinéraires

Littérature, textes, cultures

\title{
Éric Marty, Pourquoi le Xxe siècle a-t-il pris Sade au
} sérieux?

Paris, Seuil, coll. « Fictions \& Cie », 2011, 445 pages.

\section{Vincent Jolivet}

\section{(2) OpenEdition}

Journals

Édition électronique

URL : http://journals.openedition.org/itineraires/761

DOI : 10.4000/itineraires.761

ISSN : 2427-920X

Éditeur

Pléiade

\section{Édition imprimée}

Date de publication : 1 mars 2014

Pagination : 203-204

ISBN : 978-2-343-02712-8

ISSN : $2100-1340$

\section{Référence électronique}

Vincent Jolivet, « Éric Marty, Pourquoi le xxe siècle a-t-il pris Sade au sérieux ? 》, Itinéraires [En ligne], 2013-2 | 2014, mis en ligne le 01 novembre 2013, consulté le 22 septembre 2020. URL : http:// journals.openedition.org/itineraires/761 ; DOI : https://doi.org/10.4000/itineraires.761

Ce document a été généré automatiquement le 22 septembre 2020.

\section{(c) (1)}

Itinéraires est mis à disposition selon les termes de la licence Creative Commons Attribution - Pas d'Utilisation Commerciale - Pas de Modification 4.0 International. 


\section{Éric Marty, Pourquoi le $\mathrm{XX}^{e}$ siècle $a-t-i l$ pris Sade au sérieux?}

Paris, Seuil, coll. « Fictions \& Cie », 2011, 445 pages.

\section{Vincent Jolivet}

\section{RÉFÉRENCE}

Éric Marty, Pourquoi le xx siècle a-t-il pris Sade au sérieux ?, Paris, Seuil, coll. « Fictions \& Cie », 2011, 445 pages.

1 «On a toujours beaucoup moins lu Sade qu'on ne l'a commenté ». À sa manière, le remarquable ouvrage d'Éric Marty Pourquoi le $\mathrm{xx}^{\text {e }}$ siècle a-t-il pris Sade au sérieux ? vient confirmer ce propos quelque peu désenchanté d'Annie Le Brun, dont il révèle tout à la fois la pertinence et l'insuffisance relative. Car si l'histoire du rapport entretenu par la modernité avec le marquis de Sade peut apparaitre, à quelques exceptions près, comme celle d'une persistante méconnaissance de l'écrivain et de ses œuvres, auxquels est substitué leur double légendaire, il n'en demeure pas moins que cette modernité, conçue comme la période allant de l'après-guerre à la fin des années 1970, a su parfois produire des pensées d'une singulière force. De Bataille à Blanchot, de Deleuze à Foucault, Sade est sans doute moins l'objet du discours que la figure mythique présidant à son élaboration, alimentant par sa légende et la lubricité de sa parole un délire neuf et inspiré, un rationalisme autre et traversé par le désir. Plus qu'à l'œuvre de Sade, c'est à cette aventure intellectuelle que s'intéresse Éric Marty, dont il restitue brillamment les sinuosités et les ruptures, les implicites et les enjeux. On saluera la clarté du propos, la netteté de ses découpages. Dans la succession des œuvres et des noms sont ainsi distinguées quatre grandes séquences, autour desquelles se construit le livre : 1947 voit la fondation d'un sujet sadien (Adorno, Klossowski, Blanchot, Bataille) avec lequel 1961 marque le début d'une certaine prise de distance (Lacan, Foucault, Deleuze), 1967 instaure un tournant sémiotique (Klossowski, Barthes, Sollers) que vient définitivement liquider 1975 et la fin de la fête sadienne (Pasolini). À l'empathie 
brûlante des débuts succède donc le rejet fracassant, à l'identification des uns la méfiance des autres. À la liquidation d'Hegel et de sa dialectique se greffe la lutte armée contre la bourgeoisie honnie, à la lecture philosophique se substitue progressivement l'analyse sémiotique. Sade est l'annonciateur des camps de la mort comme il est l'emblème de toutes les victimes, il vient libérer l'homme normal ou l'enrégimenter dans l'injonction à dire le sexe. Dans ce grand foisonnement d'idées parfois contradictoires, Éric Marty opère des rapprochements (Adorno, Pasolini), suggère des filiations (Blanchot, Foucault). Il sait aussi se faire inattendu lorsqu'aux développements prévisibles il préfère des excursions moins évidentes. Il passe ainsi rapidement sur le Barthes structuraliste qui présentait Sade comme un fondateur de langue pour s'attarder plutôt sur celui de La Chambre claire et du Plaisir du texte, chantre du neutre et de la liberté des signes. De même pour évoquer Deleuze ne se borne-t-il pas à la Présentation de Sacher-Masoch à laquelle on limite trop souvent sa contribution, mais s'attache plutôt à dévoiler la profondeur d'un dialogue constant avec le marquis, dont l'ombre souterraine préside à l'élaboration d'une philosophie de la perversion depuis le Nietzsche et la philosophie jusqu'à Logique du sens. Au-delà de la mise en évidence de ce que ces pensées doivent à l'écrivain, l'auteur n'hésite pas par ailleurs à en relever les imprécisions ou les erreurs: au Bataille dénazifiant Sade un peu vite par l'opposition du crime passionnel et du meurtre froid des bourreaux nazis, il rappelle ainsi l'apathie des libertins qui prônent le meurtre commis sans passion; du Foucault de l'Histoire de la folie, qui fait de l'écrivain maudit son étendard, il rappelle la lecture de seconde main via Blanchot et les oublis gênants (l'épisode de Vespoli dans l'Histoire de Juliette). C'est sans doute là une autre force de ce livre, que cette solidité des connaissances de son auteur sur le marquis, qui lui permet de rectifier certains propos ou de mesurer dans le va-et-vient du réel au mythe la part d'invention des modernes. Alliant à l'érudition la rigueur et aux bonheurs d'écriture le souci de l'exhaustivité, Éric Marty signe donc avec ce Pourquoi le $\mathrm{XX}^{e}$ siècle a pris Sade au sérieux ? un ouvrage majeur, voué à faire date aussi bien dans l'histoire des études sadiennes que dans celle de la pensée du siècle dernier.

\section{AUTEURS}

\section{VINCENT JOLIVET}

Université Paris-Sorbonne, CELLF $17^{\mathrm{e}}-18^{\mathrm{e}}$ 